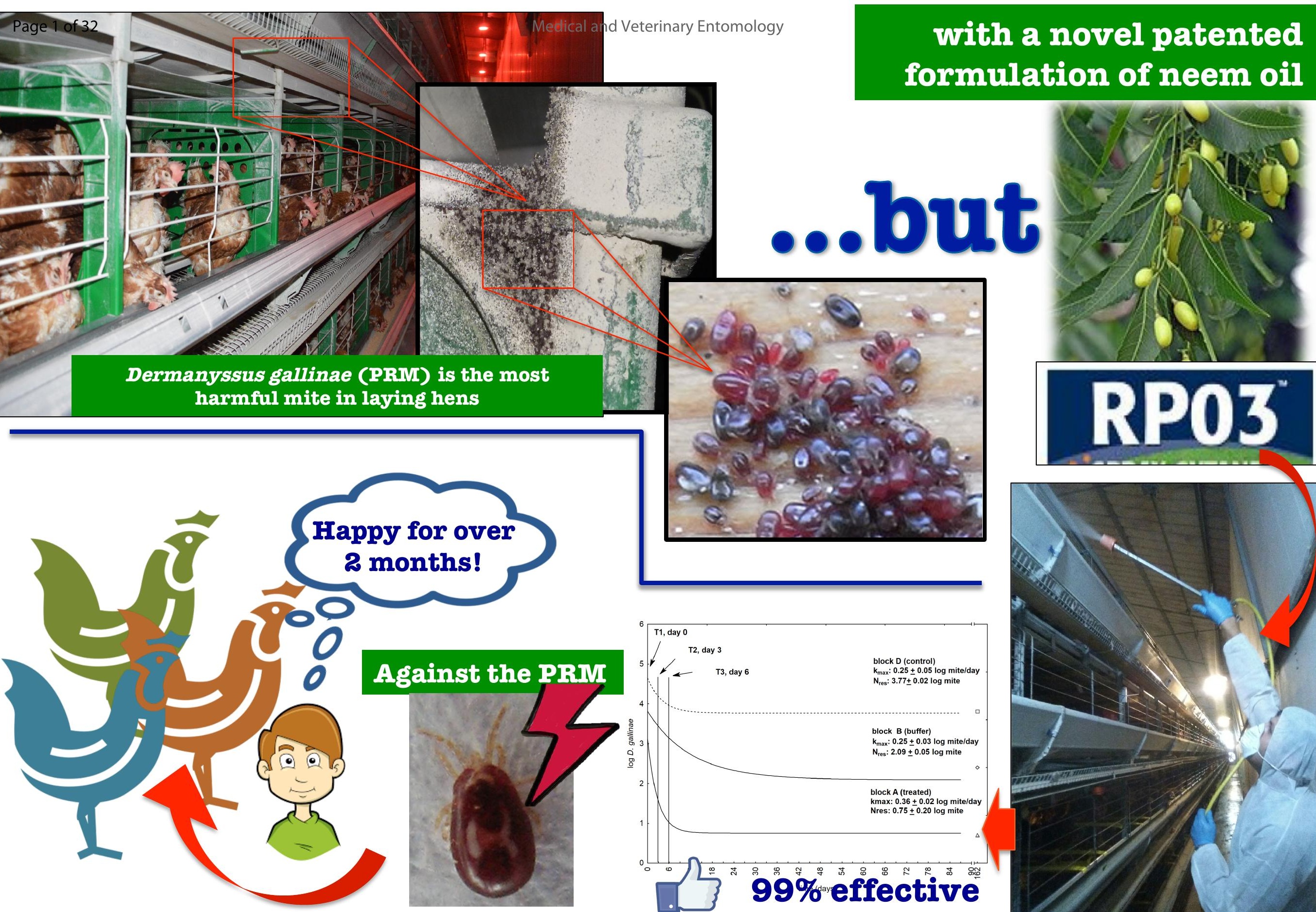


8

9
Title: Efficacy of a novel neem oil formulation $\left(\mathrm{RPO3}^{\mathrm{TM}}\right)$ to control the poultry red mite

\section{Dermanyssus gallinae}

Running title: Plant-derived product to control the poultry red mite

ANTONIO CAMARDA ${ }^{1}$, NICOLA PUGLIESE ${ }^{1}$, ANTONIO BEVILACQUA $^{2}$, ELENA CIRCELLA $^{1}$, LUIGI GRADONI ${ }^{3}, \quad$ DAVID GEORGE ${ }^{4}, \quad$ OLIVIER $\quad$ SPARAGANO ${ }^{5}, \quad$ ANNUNZIATA GIANGASPERO $^{2 *}$

${ }^{1}$ Department of Veterinary Medicine, University of Bari, 70010, Valenzano, Italy; ${ }^{2}$ Department of Science of Agriculture, Food and Environment, University of Foggia, 71121 Foggia, Italy; ${ }^{3}$ Istituto Superiore di Sanità, 00161 Roma, Italy; ${ }^{4}$ Stockbridge Technology Centre, North Yorkshire, YO8 3TZ UK; ${ }^{5}$ Centre for Agriculture and Water Resilience (CAWR), Coventry University, Coventry, CV1 5FB UK

\section{*Corresponding author:}

Annunziata Giangaspero

Department of Science of Agriculture, Food and Environment, University of Foggia, Via Napoli 25,

71121 Foggia, Italy

Tel.: 00390881.589227

E-mail address: annunziata.giangaspero@unifg.it 


\section{Abstract}

Dermanyssus gallinae is the most harmful ectoparasite of laying hens, an occupational hazard for poultry workers, and an increasing threat to medical science per se. To control the mite there is an increasing demand for alternative products, including plant-derived acaricides. We investigated the efficacy of neem oil against $D$. gallinae on a heavily infested commercial laying egg farm. A novel formulation of $20 \%$ neem oil, diluted from a 2,400 ppm azadirachtin-concentrated stock ( $\mathrm{RP} 03^{\mathrm{TM}}$ ), was administered by nebulization three times in a week. Using corrugated cardboard traps, mite density was monitored before, during and after treatment and results were statistically analyzed. Mite populations in the treated block showed a $94.65 \%, 99.64 \%$ and $99.80 \%$ reduction after the first, second and third product administration, respectively. The reduction rate of the mite population was significantly higher for the treated block $(\mathrm{P}<0.001)$ compared to the control and buffer blocks. Results suggest strong bioactivity of neem, and specifically the patented neem-based $\mathrm{RP} 03^{\mathrm{TM}}$, against $D$. gallinae. The treatment was most effective in the 10 days following the first application, and its effects persisted for over two months. Further studies will aim to overcome observed side effects of treatment caused by an oily layer on equipment and eggs.

Keywords: Azadirachta indica; Dermanyssus gallinae; acaricide; enriched colony system; laying hens; neem;zzoonosis. 


\section{Introduction}

The poultry red mite Dermanyssus gallinae (De Geer 1778) is considered the most harmful ectoparasite of farmed poultry in Europe (Sparagano et al., 2014). This haematophagous mite spends the day hidden in cracks and crevices of the chicken house, and feeds on the animals during the night (Chauve, 1998). In Europe D. gallinae is endemic, with infestation rates varying between countries. The most recent figures suggest that D. gallinae prevalence in laying hens varies from 20 to $90 \%$ in many EU countries, with an average prevalence of 83\% (Mul et al., 2013). Earlier estimates of percentage infestation in Italy were reported as 74\% (Cafiero et al., 2008), supporting increased significance of this pest over the last decade. D. gallinae is present in all poultry production systems: cages, aviaries and free range, both traditional and organic (Hoglund et al., 1995). The impact of this pest, however, is most severe in laying hens (Chauve, 1998) due to the longer productive cycle in these systems when compared with broiler farms (Giangaspero et al., 2017). Recent legislation banning conventional cage production (European Directive 1999/74/CE) has driven a shift towards more extensive and 'enriched' housing for laying hens in the EU. Such systems, however, tend to provide more complex environments that appear to favour $D$. gallinae, thus exacerbating the mites' pest status. Reports of D. gallinae feeding upon mammals, including humans, are becoming increasingly common (George et al., 2015) and it has been proposed as an occupational hazard for poultry workers (Cafiero et al., 2011). Cases of human infestation are not limited to those working in close proximity to the mite, however, with increasing numbers of attacks also reported in private residences, hospitals, and office spaces, often due to synanthropic infested birds (Cafiero et al., 2009; George et al., 2015). Though most cases are quickly resolved and involve advantitious feeding only, an apparent rise in persistant human infestations in recent years should be cause for concern.

The main detrimental effect of $D$. gallinae infestation is stressing of hens, resulting in irritation, restlessness, feather pecking, and anemia in infested flocks. Heavy infestations have a negative impact on bird condition, growth rate, egg quality (through increased shell thinning and spotting) and production

(Chauve, 1998; Cosoroaba, 2001). 
71 Consequences of infestation are worsened due to the status of this species as a vector and reservoir for

several bacterial and viral pathogens (Valiente Moro et al. 2009; Camarda et al., 2010, Circella et al., 2011; Sparagano et al., 2014).

Control of D. gallinae remains heavily reliant on the use of synthetic acaricides (i.e., carbaryl, organophosphates, permethrin). This is a matter of concern, however, as the continuous use of these products has already led to issues of resistance, treatment failure, presence of residues and animal and human welfare concerns (Marangi et al., 2009; Marangi et al., 2012; Sparagano et al., 2014). Recognising the need to develop alternatives to conventional acaricides, the worldwide scientific community is investigating the efficacy of alternative control methods for D. gallinae, including both biopesticides and biological control. Several such products have now begun to penetrate the marketplace in some EU countries (e.g. spinosad), with a mounting body of evidence supporting strong future potential in plant-derived acaricides (George et al., 2014).

Neem seed extract is proven to have activity against a wide range of pests of veterinary and medical significance, including D. gallinae (Schmahl et al., 2010). Neem-based products contain compounds including azadirachtin and salanin that are known to be bioactive against mites and insects, whilst being relatively safe for other organisms (Biswas et al., 2002). Azadirachtin acts by dispersing/blocking juvenile hormones in insects, interrupting growth and reproduction, also disrupting chitin synthesis in arachnids and insects. Salanin acts as a feeding deterrent in insects, with bioactivity also demonstrated for triterpenoids such as nimbin and nimbidin, which show antibacterial, antiviral and fungicidal properties (George et al., 2014).

Although neem-based products have already been developed for use against D. gallinae and deployed either within traps (Lundh $\boldsymbol{e t}$ al., 2005) or as premise sprays (MiteStop ${ }^{\circledR}$ Falema, Switzerland), to date these have only been tested in poultry kept in free range and conventional cage systems, with only limited studies performed to support commercial benefit and a paucity of neem-based products available for potential use. Further research to develop a novel robust neem-based acaricide, and independently confirm efficacy of neem per se in a commercial setting, would thus be of benefit. 
97

98

99

100

101

102

103

104

105

106

107

108

109

110

111

112

113

114

115

116

117

118

119

120

121

122

The above in mind, the aim of this study was to investigate the potential of a novel neem-based product $\mathrm{RP} 03^{\mathrm{TM}}$ for the control of the poultry red mite D. gallinae under field conditions, in an enriched colony egg production system. RP03 ${ }^{\mathrm{TM}}$ is a patented novel formulation (Farmaneem $\mathrm{Srl}$ ) of an extract of the seeds of the neem tree (Azadirachta indica). The product is a spray formulation containing azadirachtin (0.24\% $\min$.$) , nimbin (0.4 \% \mathrm{~min}$.$) , and salanin (0.6 \% \mathrm{~min}$.$) .$

\section{Materials and methods}

\section{Site and animals}

The study was carried out in an enriched cage unit on a commercial laying hen farm in the province of Brindisi (Apulia, Italy). The unit housed approximately 19,000 hens of a commercial genotype (Hy-line Brown and Hy-line White), which were approximately 14 months old at the start of the experiment and not previously housed in other cage facilities. The farm building was arranged in four blocks (A-D, Fig. 1) of cages, each consisting of two adjacent lines of cages, arranged over four tiers of 29 cages each (providing 116 cages per block and 464 cages in total), compliant with national and European regulation and welfare legislation. Twenty birds were housed in each cage. A forced ventilation system provided air circulation and negative pressure in the unit. Birds were fed ad libitum with a commercial layer mash and had continuous access to drinking water.

The farm was selected as the study site because of previous historical issues with $D$. gallinae, dating back several years. The infestation in the unit at the time of the study ranked at level IV according to the classification system of Cox $\boldsymbol{e t}$ al. (2009), i.e., clusters of mites (groups of mites larger than $1 \mathrm{~cm}^{2}$ ) were visible on the structures. In addition, preliminary inspections proved that the flock was properly managed and that no acaricide treatments had been applied in the 3 months prior to the trial commencing.

\section{Study design}

For assessing $D$. gallinae numbers, mites were collected in, and counted from, custom-made traps. Traps were prepared according to Nordenfors et al. (1999) with slight modifications. Namely, 100x140 mm 
123 pieces of corrugated cardboard were rolled and inserted into plastic tubes $10 \mathrm{~cm}$ long and with a diameter 124 of $3 \mathrm{~cm}$.

125 Traps were placed before, during and after the treatment which consisted of product application given 126 three times during one week. Traps were left in situ for 48 hours at each sampling point prior to the third 127 treatment, and for 72 hours at each sampling point thereafter. Collections for mite counts were performed 128 at day 0 (before the first treatment) and 3, 6, 10, 18, 27, 34, 41, 50, 59, 69, 87 and 162 days after the first 129 treatment. A detailed trapping and mite counting schedule is shown in Supplementary Table 1.

130 Mites were collected from cages on both sides of blocks A, B and D. Traps were placed in alternate 131 cages, and between the selected cages, in order to cover a wider area and according to the routes tracked 132 by mites to reach the hosts (Fig. 1). Forty traps per block (20 on each side) were placed, for a total of 120 133 traps per sampling occasion. At established times, the corrugated cardboard inserts in the traps were 134 removed from the tubes and new inserts positioned ahead of subsequent samplings (Supplementary 135 Table 1). Traps were processed for mite counting in 'blind' by the same individuals for consistency.

136 Once removed, each cardboard insert was placed individually in a plastic bag, taken to the laboratory and 137 stored at $-18{ }^{\circ} \mathrm{C}$ for $48 \mathrm{~h}$ to kill the mites present. After freezing, each trap was then opened and the mites 138 were poured into a petri dish. Mites attached to the surfaces of the tubes were gently detached using a 139 needle. Before counting, the mites were spread evenly in the petri dish and confirmed as D. gallinae 140 according to the morphological keys by Moss (1968) and Di Palma et al. (2012). All counts were made 141 under a stereomicroscope (Leica, Wetzlar, Germany), though whenever more than 500 mites were 142 present in a trap, their number was estimated by weighing. In these cases, the calibration standard was 143 determined by weighing no less than five 100-mite aliquots.

\section{Treatment application}

146 The interconnected nature of cages within a block did not allow separation of each block into treatment 147 replicates, so that treatment with the experimental neem formulation was administered to both lines of 148 cages of Block A only. It should be pointed out that a dedicated experimental structure to serve as buffer 
149 zone (such as reported by George et al., 2014), could not be employed here due to the commercial nature 150 of the facility. A formulation of $20 \%$ neem oil dilution, from a $2,400 \mathrm{ppm}$ azadirachtin-concentrated 151 stock $\left(\mathrm{RP} 03^{\mathrm{TM}}\right)$, was used and $150 \mathrm{~L}$ of this $20 \%$ solution was sprayed on the treated block by a 152 pressurized hand-held lance sprayer (Spray Team SRL, Italy), with a particles size lower than 90-100 153 thousandths of a millimeter, covering all accessible surfaces of the cage walls and floors, also treating 154 litter and animals present. Overall, a surface area of $457 \mathrm{~m}^{2}$ was treated in Block A, equating to an 155 overall volume of $237.42 \mathrm{~m}^{3}$ of treated cage space. Approximately $0.32 \mathrm{~L}$ of neem solution was applied 156 per $\mathrm{m}^{2}$.

157 Block D was selected as the negative control, this being maximally spatially separated from the treated 158 Block A, and was not subject to spraying. Block B was considered as a buffer block, in order to verify 159 possible effects on mites due to the dispersion of RP03 ${ }^{\mathrm{TM}}$. Block $\mathrm{C}$ was left untreated.

160 Records of hen mortality were kept during the study with post-mortem analysis undertaken on every dead 161 bird.

\section{Statistical analysis}

164 In order to examine the effect of treatment on D. gallinae population response, the number of $D$. gallinae 165 was preliminary standardized as $\log _{10}$ and analyzed to check for normality through the Shapiro-Wilk test. 166 Then, log-values were used to build a variability plot, showing both raw data and median value $w$ 167 throughout time.

168 Then, a second standardization was run and the data reported as log decrease of D. gallinae against the 169 starting population (log units at the beginning of the experiment - log units at time t). For this approach, 170 each line of a block was treated as a separate sample and preliminarily analyzed through the Shapiro171 Wilk test. On the $\log$ reduction values, a multifactorial ANOVA was run; time and position were use as 172 categorical predictors. The predictor "time" had 12 different coded values (log after 3, 6, 10, 18, 27, 34, $17341,50,59,69,87$ and 162 days), whereas the predictor position had 6 coded values (A-line 1; A-line 2; 174 B-line 1; B-line 2; D-line 1; D-line 2). The statistical treatment was performed using Statistica for 
175 Windows, ver. 12.0 (Statsoft, Tulsa, Oklahoma). The analysis was corrected through a "dependence 176 factor" estimated by the software. This factor takes into account that the two sides of each block could be 177 not independent due to possible mite movement between them. The term time in the multifactorial 178 ANOVA does not refer to a possible correlation time $v s$ population (XY correlation); it is only a 179 qualitative factor put in the analysis to elucidate that the population could be different for the treatment 180 and the time of sampling. The multifactorial ANOVA was run as a GLM (general linear model) to assess 181 the standard error of estimate of the whole model.

182 As a final step, the evolution of D. gallinae throughout time was fitted by using the Weibull/tail equation, 183 as reported by Geeraerd et al. (2005). This model allows the estimation of $\mathrm{k}_{\max }$, here akin to the rate of 184 D. gallinae reduction, $\mathrm{N}_{\text {res }}$.

185

186

Results

Pre-treatment infestation by D. gallinae

On day 0 (before treatment), mean counts of mites $( \pm$ SD) were 48,284 $\pm 15,864,9,594 \pm 7,430$, and 3,049 \pm 4,689 in control, buffer and treated block, respectively (Supplementary Table 2).

Post-treatment D. gallinae population monitoring evaluation

192 According to the first step of the statistical approach, in the control block (Fig. 2A), the initial median 193 value was $4.65 \log$ D. gallinae. This figure decreased to $3.25 \log$ D. gallinae after 59 days and increased 194 to $3.91 \log$ D. gallinae at the end of the study period (162 days). In the buffer block (Fig. 2B), the initial 195 median number was $3.90 \log$ D. gallinae and was reduced to $1.56 \log$ D. gallinae after 59 days, 196 increasing to $2.77 \log$ D. gallinae after 162 days. In the treated block (Fig. 2C), the mite population was 197 reduced from $3.11 \log$ D. gallinae to $0.39 \log$ D. gallinae after 10 days, then experiencing a slight 198 increase (up to $1.15 \log$ units after 27 days), with a final decrease and a biostatic effect, as suggested by the median mite value, ranging from 0.48 to $0.98 \log$ units. 
200 The plots in Fig. 2 show all raw data and suggest strong variability within each block. In addition, when

201 both lines were used as replicates of a single block, the residuals of some samples did not follow a normal

202 distribution; conversely, each line of a block, treated as a separate sample, showed a normal distribution

203 and satisfied the basic assumptions of the analysis of variance (normal distribution of residuals,

204 homoscedasticity). Therefore, the lines were treated as separate samples and a second standardization was

205 done (log mite decrease) to compare the different blocks. Each sample was analysed as a function of the

206 time and position (lines of each block).

207 Table 1 shows F-test outputs and the standardized effects. "Position" and "Time" were both significant 208 as individual predictors, although the most significant was "position", according to the F-test. The log209 reduction was also significantly affected by the interactive term position/time. ANOVA was run via a 210 GLM (general linear model) and the standard error of estimate of the model was $0.53 \log$ D. gallinae. In

211 using a GLM the non-independence of the two sides of each block, and the time-dependency of the 212 effect, could be taken into account in the analysis: however, the main goal of this research was to assess 213 the effect of a main qualitative variable (treatment: control, buffer, treated row), a secondary qualitative 214 variable (sides of each block) and a quantitative factor (time).

215 Time-dependence was expected, whereas the qualitative effect of the treatment (reduction or no reduction 216 of mite population) could be better determined by a qualitative approach, like ANOVA.

217 In this respect, log-transformation and log reduction were used as a means to calculate a standard 218 efficiency index that was independent from the initial mite count and less affected by the outliers.

219 A second output of a multifactorial ANOVA is the decomposition of the statistical hypothesis; as 220 reported elsewhere (Bevilacqua et al., 2017), the decomposition does not show actual values or effective 221 trends, but a qualitative correlation on how each predictor acts on the dependent variable (log reduction 222 of the number of D. gallinae). Concerning the effect of position (Fig. 3A), the highest mean reduction 223 was found for Block A (2.1-2.3 log-reduction). In the buffer block (Block B), the two lines experienced a 224 slight difference (1.5 log-reduction for the line 1 and 1.2 log-reduction for the line 2$)$. Finally, in the 225 control block (Block D), the mean reduction was 0.8 log-mite $(\mathrm{P}<0.01)$. 
226 The effect of the predictor time (Fig. 3B) suggests that the population of D. gallinae experienced a 227 decrease throughout time with the maximum reduction achieved after 59 days $(\mathrm{P}<0.01)$. Fig. 3C 228 combines the predictor position and time and shows the log-reduction for each line in each block 229 throughout time. In the treated block (A), the mean of mite-reduction was $>90 \%$ after 3 days, then it 230 increased to $99 \%$ or more. After 3 days, the mean log-reduction was $40-63 \%$ in the control and buffer 231 blocks ( $\mathrm{D}$ and $\mathrm{B})$; thereafter, it increased and was $>90 \%$ in the buffer block after 18 days $(\mathrm{P}<0.05)$.

232 An increase in log-reduction was also recovered in the control block (D), due to the main effect of the 233 predictor time and to a decrease of mite population independently from the treatment. In this block, a 234 mean effect of $90 \%$ (1-log reduction) was found after 41 days; moreover, the log-reduction for this block 235 was always lower than the values found for the buffer and the treated blocks.

236 As indices of the effect of Neem on the mites, the log-reduction after the $1^{\text {st }}, 2^{\text {nd }}$ and $3^{\text {rd }}$ treatment was 237 evaluated: it was $94.65 \%, 99.64 \%$ and $99.80 \%$ in the treated block (Block A), 59.93\%, 75.68\% and $23883.68 \%$ in the buffer (Block B) and 63.24\%, 80.02\% and 82.27\% in the control (Block D).

239 Fig. 4 shows more intuitively the evolution of $D$. gallinae throughout time. As reported elsewhere, the 240 mite population experienced a reduction throughout time in all the blocks; however, the rate of 241 population decrease (0.36 log mite/day in the treated Block A vs $0.25 \log$ mite/day in the control and 242 buffer blocks, $\mathrm{P}$ at 0.023$)$ and the residual population $(0.75 \log$ mite in the treated Block A, $2.09 \log$ mite 243 in Block B and $3.77 \log$ mite in Block D) support a significant effect of the neem oil in controlling $D$. 244 gallinae (where $\mathrm{P}=0.0001)$.

\section{Hens' response to treatment}

247 One hundred and seventy six birds, i.e., $0.9 \%$ of the total number of hens present, died during the course 248 of the study. This figure is below the normal mortality rate for Hy-line Brown and Hy-line White hens of 249 the age used, which is $0.3-0.5 \%$ of the flock per month. Seven animals died prior to the application of 250 treatment. Post-mortem examination performed on all birds showed no unusual causes of death. Chronic 251 respiratory syndrome characterized by aerosacculits, catarrhal ovary and oviduct inflammation, 
252

253

254

255

256

257

258

259

260

261

262

263

264

265

266

267

268

269

270

271

272

273

274

275

276

277

caseous peritonitis, caused by E. coli and/or Mycoplasma, were the most frequently observed causes of death. Other deaths were due to accidental injuries. In no instance was any mortality event deemed treatment related.

\section{Discussion}

This study is the first to investigate neem efficacy in laying hens housed within an enriched colony system and supports that $\mathrm{RP} 03^{\mathrm{TM}}$ neem-based product is highly effective against $D$. gallinae. The product caused a very high reduction of the mite population, this exceeding $99 \%$ following the second treatment, and with long-lasting effects.

The results of mite trapping before the trial demonstrated that the D. gallinae population was not uniformly distributed across cage blocks. Differences in number of mites registered in one block compared to another were not completely unexpected, and they could be related to uncontrollable variables present in the laying system, such as location, humidity, air-flow, temperature, hen breed, etc.

(Nordenfors \& Höglund, 2000; Arkle et al., 2004). Pre-existing differences in mite burden between control and treated blocks may be considered a limitation in the present study, as differences in the initial number of mites (i.e. a higher mite burden in the control block) could have potentially affected the output of statistical analyses. This event could not be avoided due to a number of factors, such as the limited availability of study sites and suitable facility design, intrinsic mite population variability within each facility, and inevitable lag times occurring between trap collection and assessment of trap contents. Because of the above, it was necessary to pre-set treatment block locations based on spatial arrangement alone and not on mite counts parameters (Fig. 1).

Nevertheless, to overcome this bias and avoid the effect of a possible intrinsic variability of each block, a preliminary standardization was done, by using the initial values as a baseline or internal reference for each control. This approach relies on the fact that an input factor (i.e. the use of neem oil in this study) affects the trend of the statistical population, but with the effect of the trend being independent from the initial value (Bevilacqua et al., 2016). 
278 Treatment with neem-based product provided a thousand-fold reduction of the mite population after the 279 second treatment (99.64\%) in the current study, this reaching $99.80 \%$ after the third treatment. Even after 280 the first treatment alone, a 94\% reduction in the mite population in treated blocks was observed. In 281 addition to this strong acaricidal effect and rapid knockdown of D. gallinae, the effect of treatment 282 persisted for more than two months.

283 The reduction rate of the mite population was significantly higher for the treated block $(\mathrm{P}<0.001)$ 284 compared to the buffer and control blocks. Nevertheless, it was also possible to observe a reduction in the 285 population of the latter two blocks over the study duration. Though this could potentially be explained by 286 the above mentioned fluctuations in environmental conditions, which are well known to affect $D$. 287 gallinae population density (Nordenfors \& Höglund, 2000; Arkle et al., 2004), it is also possible that 288 the dispersal of $\mathrm{RP} 03^{\mathrm{TM}}$, due to the forced ventilation in the unit, contributed to reduce the number of 289 mites in the blocks adjacent to the treated one, this being supported by the fact that the reduction seen 290 was stronger nearer to the treated block. Trap position was the most significant variable, as well as the 291 interactive term time/trap position. Trap position showed a mean mite log-reduction of ca. 2.2-2.4 for the 292 treated block, while in the control and buffer areas the mean reduction was 0.8 and 1.3, respectively. 293 These results were independent from the effect of time and suggest a strong bioactivity of neem.

294 After the first, the second and the third treatment, no side effects of neem were observed on laying hens, 295 with no birds displaying anomalous behavior. Furthermore, anecdotal evidence provided by the poultry 296 unit owner supported that no decrease in egg production was apparent post-treatment. Negative effects 297 were, however, reported on the equipment (conveyor belt, and cage structures), on the floor and, more 298 importantly, on eggs. The presence and the persistence of an oily film were observed for about 20 days 299 after the third treatment, while a characteristic smell tainted the eggs laid in the 24 hours after treatment, 300 likely due the contamination of the conveyor belt. Such side effects could be mitigated, at least partially, 301 by using a reduced volume of solution, or by reducing the size of the aerosol droplets. Reduced repeat 302 treatment schedules could also be of benefit in minimising negative effects. Due to the reclusive life cycle 303 of D. gallinae, repeat application of up to three times in a week is often recommended (Abel-Gaffar et 
304

305

306

307

308

309

310

311

312

313

314

315

al., 2009; Locher et al., 2010) to ensure that the generation emerging from hard-to-treat refugia postinitial treatment is targeted along with any existing nymphs and adults (George $\boldsymbol{e t}$ al., 2010). However, given the high efficacy ( $>99 \%$ ) of RP03 ${ }^{\mathrm{TM}}$ after the second treatment, two treatments in a week might be considered as sufficient.

Worldwide, control of $D$. gallinae infestation is based almost exclusively on the use of synthetic acaricides. Despite more than 35 molecules having been tested for use against D. gallinae (including organophosphates, pyrethrins, pyrethroids, carbamates and amitraz), in practice, only a few products are licensed in the EU for use against this pest (Sparagano et al., 2014). Perhaps as a consequence, several unlicensed or even banned (i.e. carbaryl) products are still widely used to fight infestations in some European countries (Sparagano et al., 2014). Recently, for example, mass recall of eggs across Europe and Asia occurred due to fipronil contamination, resulting in investigations into misuse/illegal use of this product by pest control to target D. gallinae (https://www.food.gov.uk/newsupdates/news/2017/16463/update-on-fipronil-in-eggs), which involved also Italy (http://www.salute.gov.it/portale/news/p3 2_1_1_1.jsp?lingua $=$ italiano\&menu=notizie\&p=dalministero $\underline{\& \mathrm{id}=3058}$ ). To promote improved product use, there is an urgent need to identify alternative, costeffective and efficacious control strategies. Among the natural compounds of use to this end (Sparagano et al., 2014; George et al., 2014), in vivo experiments using neem-impregnated cardboard traps have been shown to reduce $D$. gallinae populations by more than 90\% (Lundh et al., 2005) and a neem registered product $\left(\right.$ MiteStop $\left.{ }^{\circledR}\right)$, diluted at 1:33 with tap water, not only killed all stages of D. gallinae, but also did so more effectively than the synthetic organophosphate phoxim (Abdel-Gaffar et al., 2009). Given that prolonged efficacy was registered at 162 days post-treatment in the current study (up to $90 \%$ in the treated block), $\mathrm{RP} 03^{\mathrm{TM}}$ appears to deliver significant residual control of D. gallinae (i.e. of at least 3 months).

\section{Conclusion}

This field study demonstrated a very high and long-lasting efficacy of neem-based product $\left(\mathrm{RP} 03^{\mathrm{TM}}\right)$ 
330 against $D$. gallinae in enriched colony cages. For its characteristics of safety for animals and humans

331 (Biswas et al., 2002), azadirachtin-based products, and in particular the patented RP03 ${ }^{\mathrm{TM}}$-product tested 332 here, can be suggested for D. gallinae control, not only in the poultry sector, but also in private and 333 public settings (residences, hospital, offices). Nevertheless, further studies should be undertaken to 334 reduce the treatment schedule, optimise the neem oil concentration and consistency and independently 335 confirm product safety. Such research should help to guarantee a high efficacy, high safety and long336 lasting neem acaricide, overcoming potentially undesirable effects of the registered product on poultry 337 equipment and eggs.

\section{Ethical statement}

340 The experiment described was authorized by the Ethical Committee for Animal Welfare of the University 341 of Foggia (Prot. n. 004-2016). The treatments did not cause detriment to the birds, and no animals were 342 sacrificed. The health and welfare conditions of the flock were assessed by independent expert veterinary 343 personnel to ensure that animals did not receive any kind of damage of suffering during and after this 344 study.

\section{Acknowledgments}

347 The authors acknowledge Farmaneem Srl for provision of neem product for testing. The study was 348 carried out within the activities of the European Cooperation in Science and Technology (COST Action 349 (FA1404 - COREMI) "Improving current understanding and research for sustainable control of the 350 poultry red mite Dermanyssus gallinae.

351 The authors declare that they have no conflicts of interest. 352 
353

354

355

356

357

358

359

360

361

362

363

364

365

366

367

368

369

370

371

372

373

374

375

376

377

378

\section{References}

Abel-Gaffar, F., Semmler, M., Al Rasheid K., Melhorn H. (2009) In vitro efficacy of ByeMite and MiteStop on developmental stages of the red chicken mite Dermanysssus gallinae. Parasitology Research, 105, 1469-1471.

Arkle, S., Guy, J.H., Blackett, S.M., Sparagano, O. (2004) Variation in the population of Dermanyssus gallinae in a free range laying unit and effectiveness of chemical control. British Poultry Science, 45, S45-S46.

Bevilacqua, A., Costabile, A., Bergillos-Meca, T., Gonzalez, I., Landriscina, L., Ciuffreda, E., D’Agnello, P., Corbo, M.R., Sinigaglia, M., Lamacchia C. (2016) Impact of gluten-friendly bread on the metabolism and function of in vitro gut microbiota in healthy humans and coeliac subjects. Plos One, 11, e0162770.

Bevilacqua, A., Cibelli, F., Raimondo, M.L., Carlucci, A., Lops, F., Sinigaglia, M., Corbo, M.R. (2017) Fungal bioremediation of olive mill wastewater: using a multi-step approach to model inhibition or stimulation. Journal of the Science of Food and Agriculture, 97, 461-468.

Biswas, K. Chattopadhyay, I., Banerjee, R.K., Bandyopadhyay, U. (2002) Biological activities and medicinal properties of neem (Azadirachta indica). Current Science, 8, 1336-1345.

Cafiero, M.A., Camarda, A., Circella, E., Raele, D., Giangaspero, A., Sparagano, O.A.E. (2008) Dermanyssus gallinae prevalence in laying hen units in the Apulia Region, Italy. Proceedings of the British Society for Parasitology. 167 BSP048.

Cafiero, M.A., Camarda, A., Circella, E., Galante, D., Lomuto, M. (2009) An urban outbreak of red mite dermatitis in Italy. International Journal of Dermatology. 48, 1119-1121.

Cafiero, M.A., Galante, D., Camarda, A., Giangaspero, A., Sparagano, O. (2011) Why dermanyssosis should be listed as an occupational hazard. Occupational Environmental Medicine, 68, 628.

Camarda, A., Circella E., Palese A., Stonfer M., Marangi M., Cafiero M.A., Giangaspero A., Sparagano O.A.E. (2010) Evaluation of the acaricide efficacy of phoxim in red mite Dermanyssus gallinae 
379

380

381

382

383

384

385

386

387

(Acarina: Dermanyssidae) field populations from Italy. Proceedings of XIII European Poultry Conference. 23-27 August, Tours, France, p. 56.

Chauve, C. (1998) The poultry red mite Dermanyssus gallinae (De Geer, 1778): current situation and future prospects for control. Veterinary Parasitology, 79, 239-245.

Circella, E., Pugliese, N., Todisco, G., Cafiero, M.A., Sparagano, O.A., Camarda, A. (2011) Chlamydia psittaci infection in canaries heavily infested by Dermanyssus gallinae. Experimental Applied Acarology, 55, 329-338.

Cosoroaba, I. (2001) Massive Dermanyssus gallinae invasion in batteryhusbandry raised fowls. Revue de Médicine Véterinaire, 152, 89-96.

Cox, M., De Baere, K., Vervaet, E., Zoons, J., Fiks-Van Niekerk, T. (2009) Red mites: monitoring method and treatment. Proceedings of 8th European symposium on poultry welfare, Cervia, Italy, 18-22 May, p. 83.

Di Palma, A., Giangaspero, A., Cafiero, M.A., Germinara, G.S. (2012) A gallery of the key characters to ease identification of Dermanyssus gallinae (Acari: Gamasida: Dermanyssidae) and allow differentiation from Ornithonyssus sylviarum (Acari: Gamasida: Macronyssidae). Parasite \& Vectors, 5, 104.

Geeraerd, A.H., Valdramidis, V.P., Van Impe, J.F. (2005) GInaFiT, a freeware tool to assess non-loglinear microbial survivor curves. International Journal of Food Microbiology, 102, 95-105.

George, D.R., Olatunji, G., Guy, J.H., Sparagano, O.A.E. (2010) Effect of plant essential oils as acaricides against the poultry red mite, Dermanyssus gallinae, with special focus on exposure time. Veterinary Parasitology, 169, 222-225.

George, D.R., Finn, R.D., Graham, K.M., Sparagano, O.A. (2014) Present and future potential of plantderived products to control arthropods of veterinary and medical significance. Parasite \& Vectors, 7, 28 .

George, D.R., Finn, R.D., Graham, K.M., Mul, M.F., Maurer, V., Moro, C.V., Sparagano, O.A. (2015) Should the poultry red mite Dermanyssus gallinae be of wider concern for veterinary and medical 
science? Parasite \& Vectors, 8, 178.

Giangaspero, A., Camarda A., Cafiero M.A., Marangi M., Sparagano O. (2017) Dermanyssus gallinae: A never-ending story for the poultry industry and public health. Nova Acta Leopoldina NF, 411, 1-17.

Hoglund, J., Nordenfors, H., Uggla, A. (1995) Prevalence of the poultry red mite, D. gallinae, in different types of production systems for egg layers in Sweden. Poultry Science, 74, 1793-1798.

Locher, N., Al-Rasheid, K.A.S., Abdel-Ghaffar, F., Mehlhorn H. (2010) In vitro and field studies on the contact and fumigant toxicity of a neem-product (Mite-Stop ${ }^{\circledR}$ ) against the developmental stages of the poultry red mite Dermanyssus gallinae. Parasitology Research, 107, 417-423.

Lundh, J., Wiktelius, D., Chirico, J. (2005) Azadirachtin-impregnated traps for the control of Dermanyssus gallinae. Veterinary Parasitology, 130, 337-342

Marangi, M., Cafiero, M.A., Capelli, G., Camarda, A., Sparagano, O.A.E., Giangaspero, A. (2009) Evaluation of the poultry red mite, Dermanyssus gallinae, (Acari: Dermanyssidae), susceptibility to some acaricides in field populations from Italy. Experimental Applied Acarology, 48, 11-18.

Marangi, M., Morelli, V., Pati, S., Camarda, A., Cafiero, M.A., Giangaspero, A. (2012) Acaricide residues in laying hens naturally infested by red mite Dermanyssus gallinae. Plos One, 7, e31795.

Moss W.W. (1968) An illustrated key to the species of the acarine genus Dermanyssus (Mesostigmata: Laelapoidea: Dermanyssidae). Journal of Medical Entomology, 5, 67-84.

Mul, M., Van Riel J.W., Niekerk, T., Meerburg, B., Dicke, M., George, D., Groot Koerkamp, P. (2015) Validation of an automated mite counter for Dermanyssus gallinae in experimental laying hen cages Exp Appl Acarol (2015) 66:589-603

Nordenfors, H., and Höglund, J. (2000) Long term dynamics of Dermanyssus gallinae in relation to mite control measures in aviary systems for layers. British Poultry Science, 41, 533-540.

Nordenfors, H., Höglund, J., Uggla, A. (1999) Effects of temperature and humidity on oviposition, molting, and longevity of Dermanyssus gallinae (Acari: Dermanyssidae). Journal of Medical Entomology, 36, 68-72.

Schmahl, G., Al-Rasheid, K.A.S., Abdel-Ghaffar, F., Klimpel, S., Mehlhorn, H. (2010) The efficacy of 
431 neem seed extracts (Tre-san ${ }^{\circledR}$, MiteStop $\left.{ }^{\circledR}\right)$ on a broad spectrum of pests and parasites. 432 Parasitology Research, 107, 261-269.

433 Sparagano, O.A.E., George, D.R., Harrington, D., Giangaspero, A. (2014) Significance and control of the 434 poultry red mite, Dermanyssus gallinae. Annals Review of Entomology, 59, 447-466.

435 Valiente Moro, C., De Luna, C.J., Tod, A., Guy, J.H., Sparagano, O.A.E., Zenner, L. (2009) The poultry 436 red mite (Dermanyssus gallinae): a potential vector of pathogenic agents. In: Sparagano, O.A.E. 437 (Ed.), Control of poultry mites (Dermanyssus). Experimental Applied Acarology, 48, 93-104. 
439

440

441

442

443

444

445

446

447

448

449

450

451

452

453

454

455

456

457

458

459

460

461

462

463

464

\section{FIGURE LEGENDS}

Fig. 1. Schematic representation of the experimental design used to test in vivo acaricidal activity of neem-based RP03 ${ }^{\mathrm{TM}}$ against Dermanyssus gallinae. The farm building was arranged in four blocks (A-D) of cages, each consisting of two adjacent lines of cages arranged over four tiers of 29 cages each (providing 116 cages per block and 464 cages in total). Traps were placed in an alternating pattern on each tier and each line.

Fig. 2. Variability plot for the population of Dermanyssus gallinae throughout time in the control (block D) (A), buffer (block B) (B) and treated (block A) (C). The points indicate the log value for each trap, the line shows the median value of each block.

Fig. 3. Decomposition of the statistical hypothesis for the predictors on the multifactorial ANOVA. A) Effect of the position; B) Effect of time; C) Effect of the interaction position/time. The bars indicate the 95\%-confidence intervals.

Fig. 4. Evolution of Dermanyssus gallinae. $\mathrm{k}_{\max }=$ rate of population decrease; $\mathrm{N}_{\mathrm{res}} /=$ survivors (mean values \pm standard error). $\mathrm{T} 1=1^{\text {st }}$ treatment; $\mathrm{T} 2,2^{\text {nd }}$ treatment; $\mathrm{T} 3,3^{\text {rd }}$ treatment.

The population evolution is fitted up to 87 days, though the last point shown indicates the mean values of the mite population after 162 days.

\section{Supporting Information files}

Table S1. Scheme of the trial schedule

Table S2. Number of Dermanyssus gallinae registered throughout the trial in Treated (A), Buffer (B) and Control (D) blocks, on one side of the block line (1), on the other side of the block line (2) and average on both lines (mean value of 1 and 2). 
465

466

467 
1 Table 1. Standardized effects of the multifactorial ANOVA. The analysis was run by using the GLM

2 option in Statistica; the standard error of the model was $0.53 \log$ Dermanyssus gallinae.

3

\begin{tabular}{lccccc}
\hline & SS & df & MS & F & P value \\
\hline Intercept & $3,262.845$ & 1 & $3,262.845$ & $11,590.47$ & $<0.01$ \\
Position & 461.976 & 5 & 92.395 & 328.21 & $<0.01$ \\
Time & 161.962 & 11 & 14.724 & 52.30 & $<0.01$ \\
Position/time & 67.919 & 55 & 1.235 & 4.39 & $<0.05$ \\
Error & 385.107 & 1.368 & 0.282 & &
\end{tabular}

4 SS, sum of squares; MS, mean sum of squares; df, degree of freedom; F, Fisher test.

5

6 

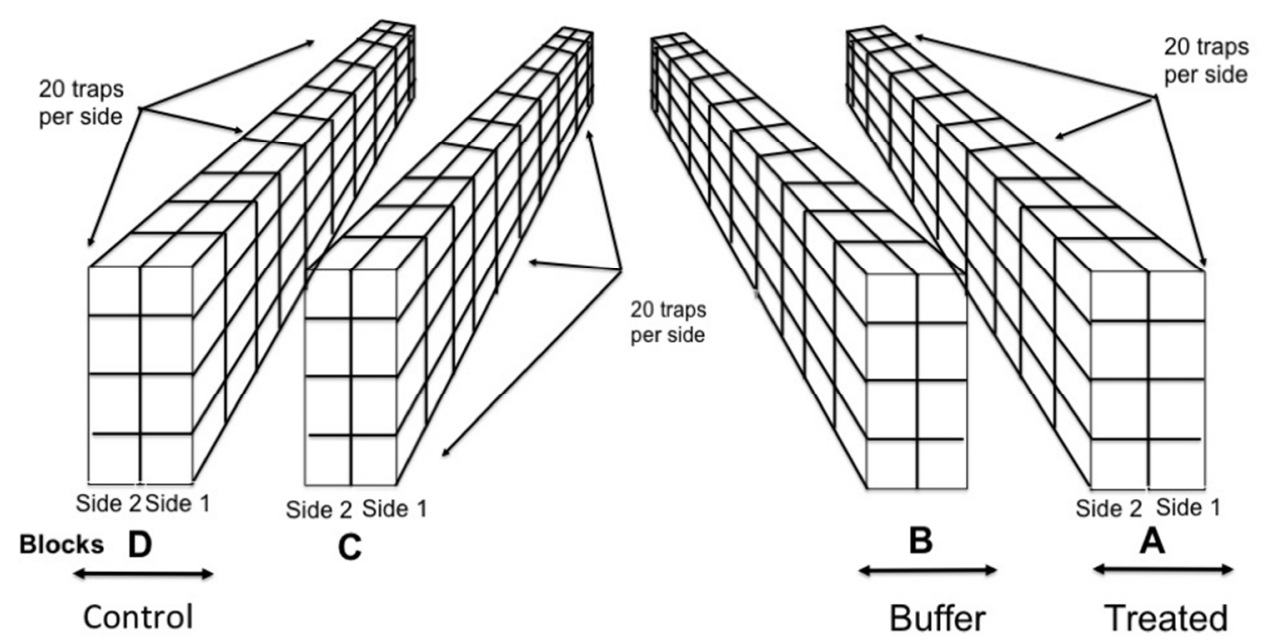

Fig. 1. Schematic representation of the experimental design used to test in vivo acaricidal activity of neembased RP03TM against Dermanyssus gallinae. The farm building was arranged in four blocks (A-D) of cages, each consisting of two adjacent lines of cages arranged over four tiers of 29 cages each (providing 116 cages per block and 464 cages in total). Traps were placed in an alternating pattern on each tier and each line.

$170 \times 81 \mathrm{~mm}(150 \times 150 \mathrm{DPI})$ 


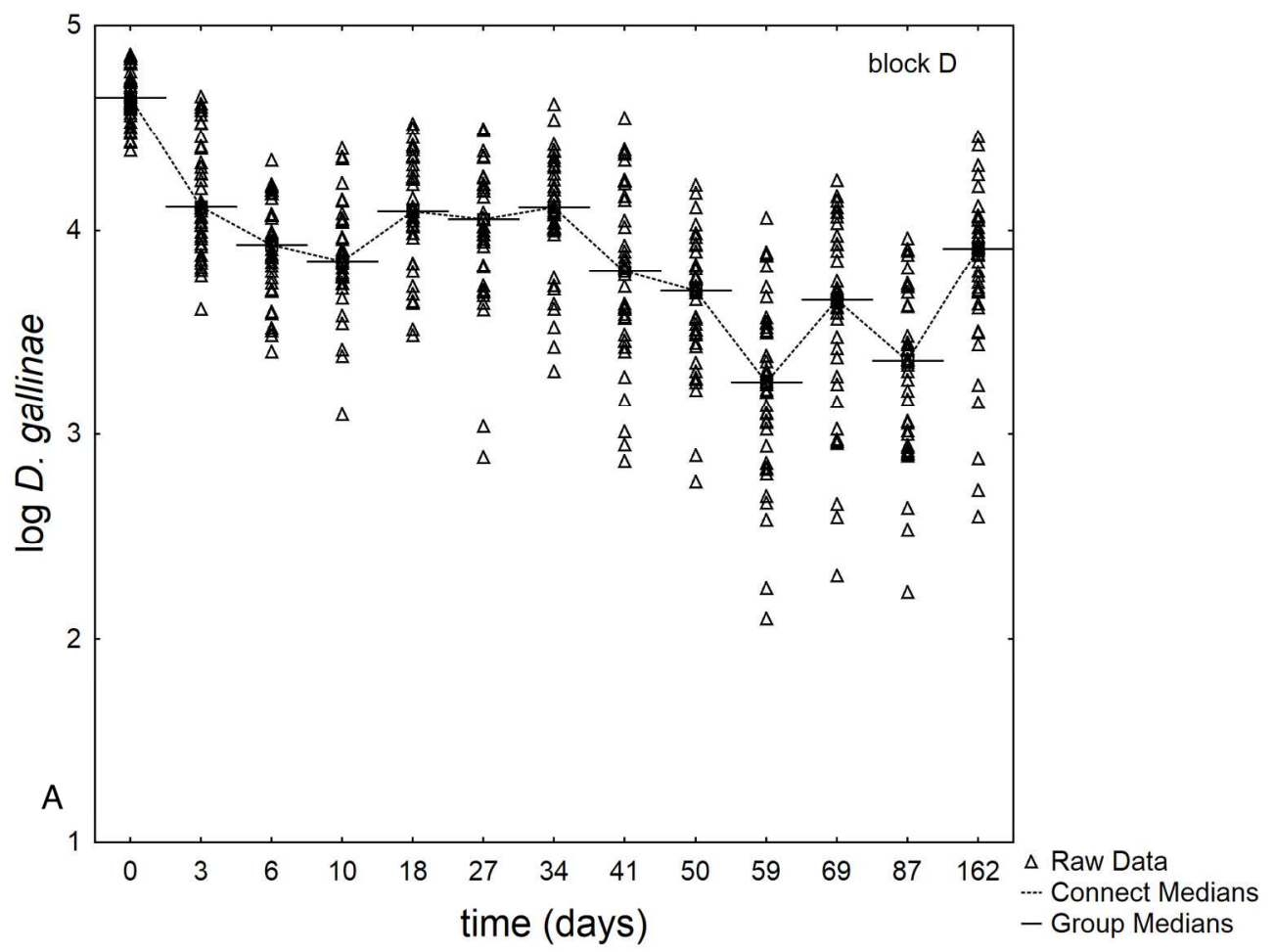

Fig. 2. Variability plot for the population of Dermanyssus gallinae throughout time in the control (block $D$ ) $(A)$, buffer (block $B)(B)$ and treated (block $A)(C)$. The points indicate the log value for each trap, the line shows the median value of each block.

$515 \times 387 \mathrm{~mm}(96 \times 96 \mathrm{DPI})$ 


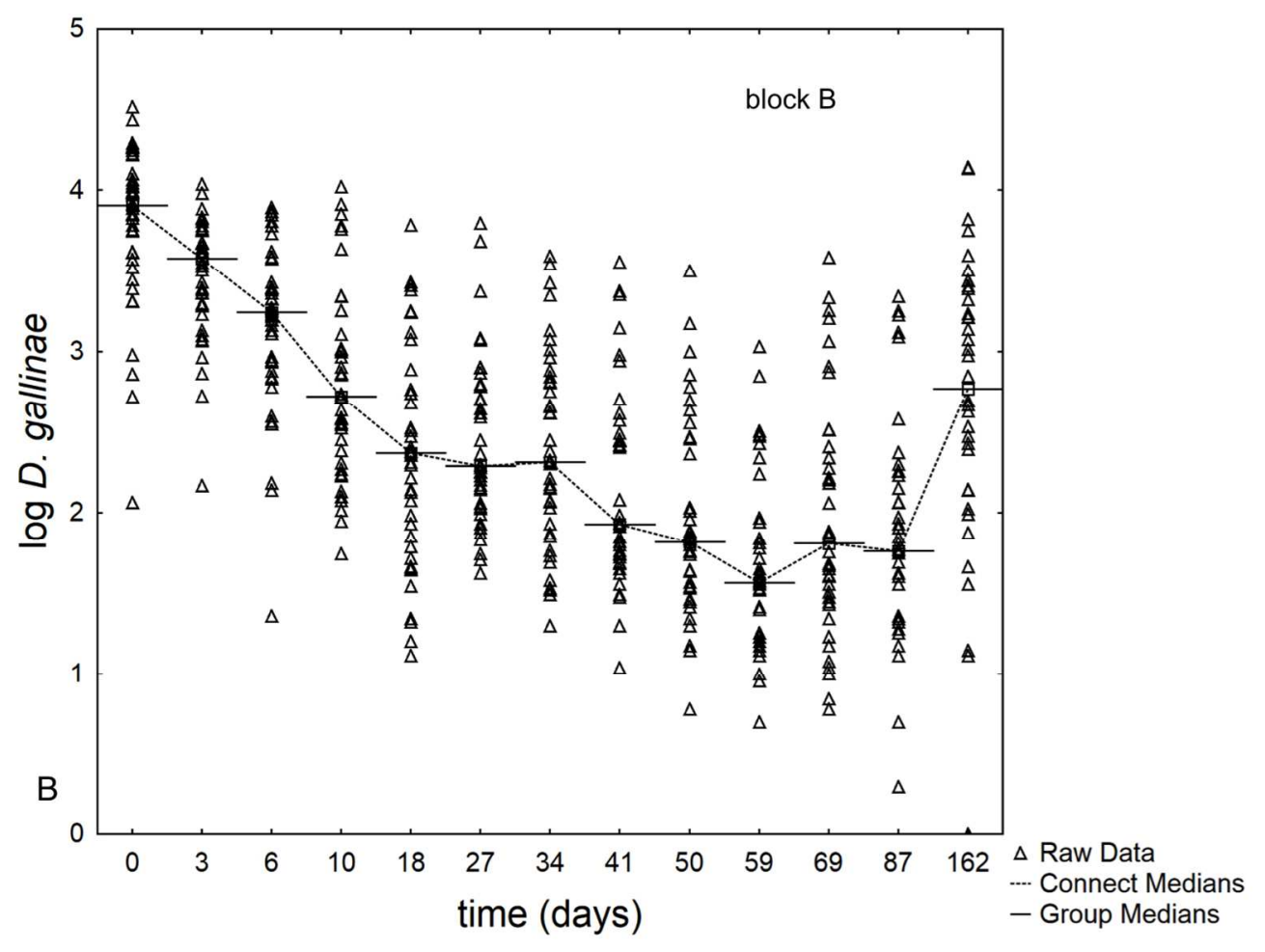

$254 \times 190 \mathrm{~mm}(150 \times 150 \mathrm{DPI})$ 


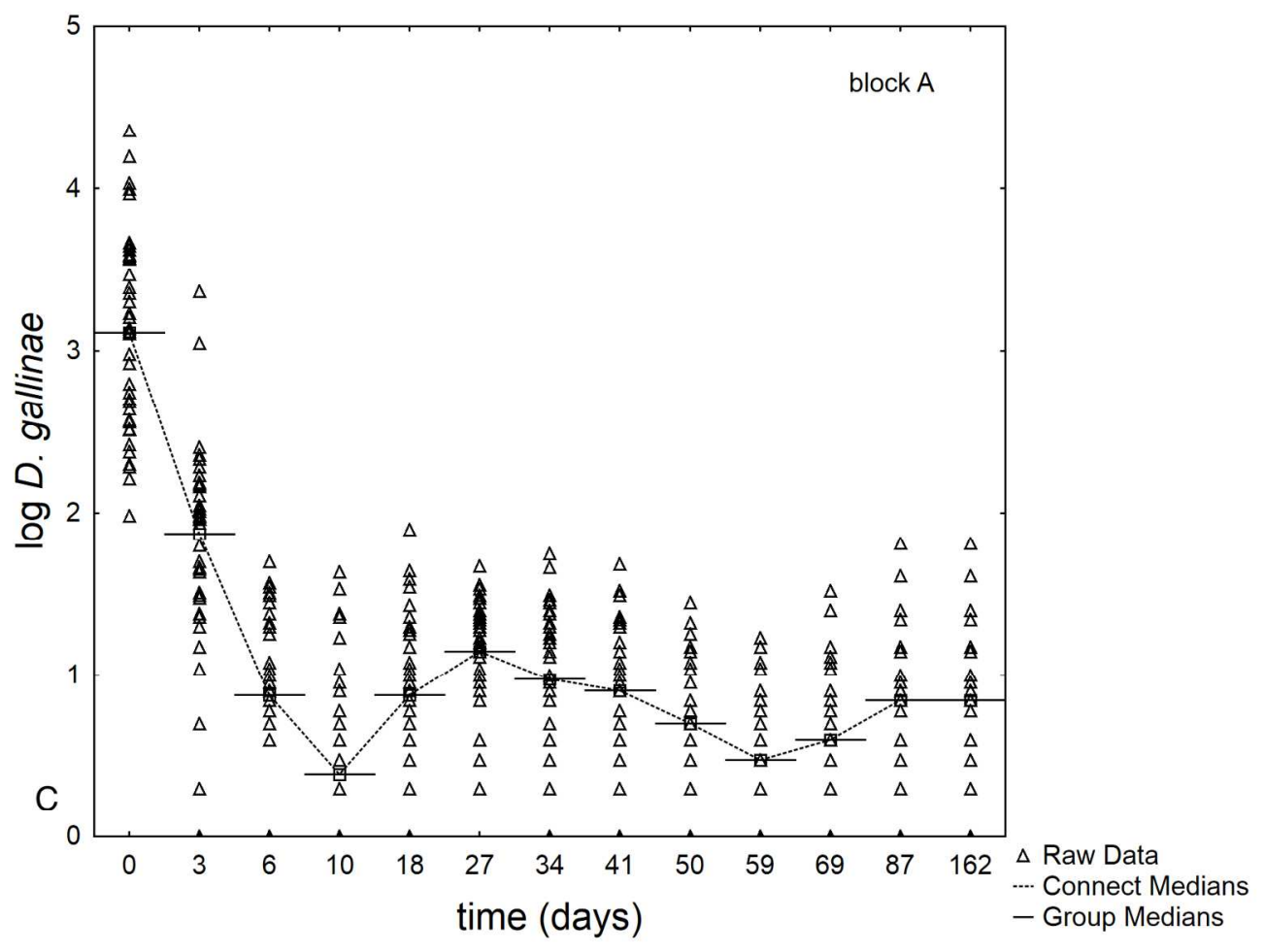

$515 \times 387 \mathrm{~mm}(96 \times 96$ DPI) 


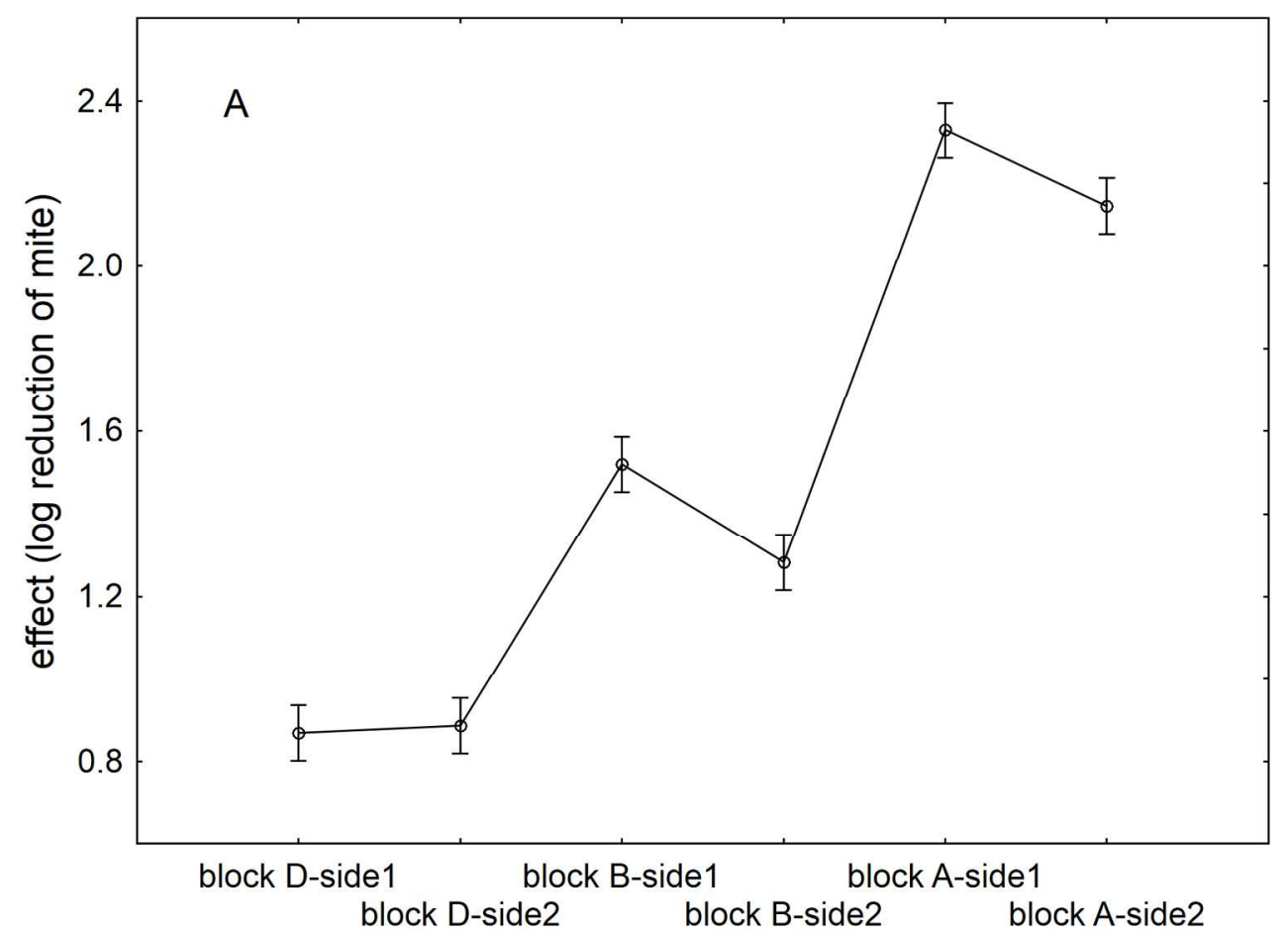

Fig. 3. Decomposition of the statistical hypothesis for the predictors on the multifactorial ANOVA. A) Effect of the position; B) Effect of time; C) Effect of the interaction position/time. The bars indicate the $95 \%$ confidence intervals.

$515 \times 387 \mathrm{~mm}(96 \times 96 \mathrm{DPI})$ 


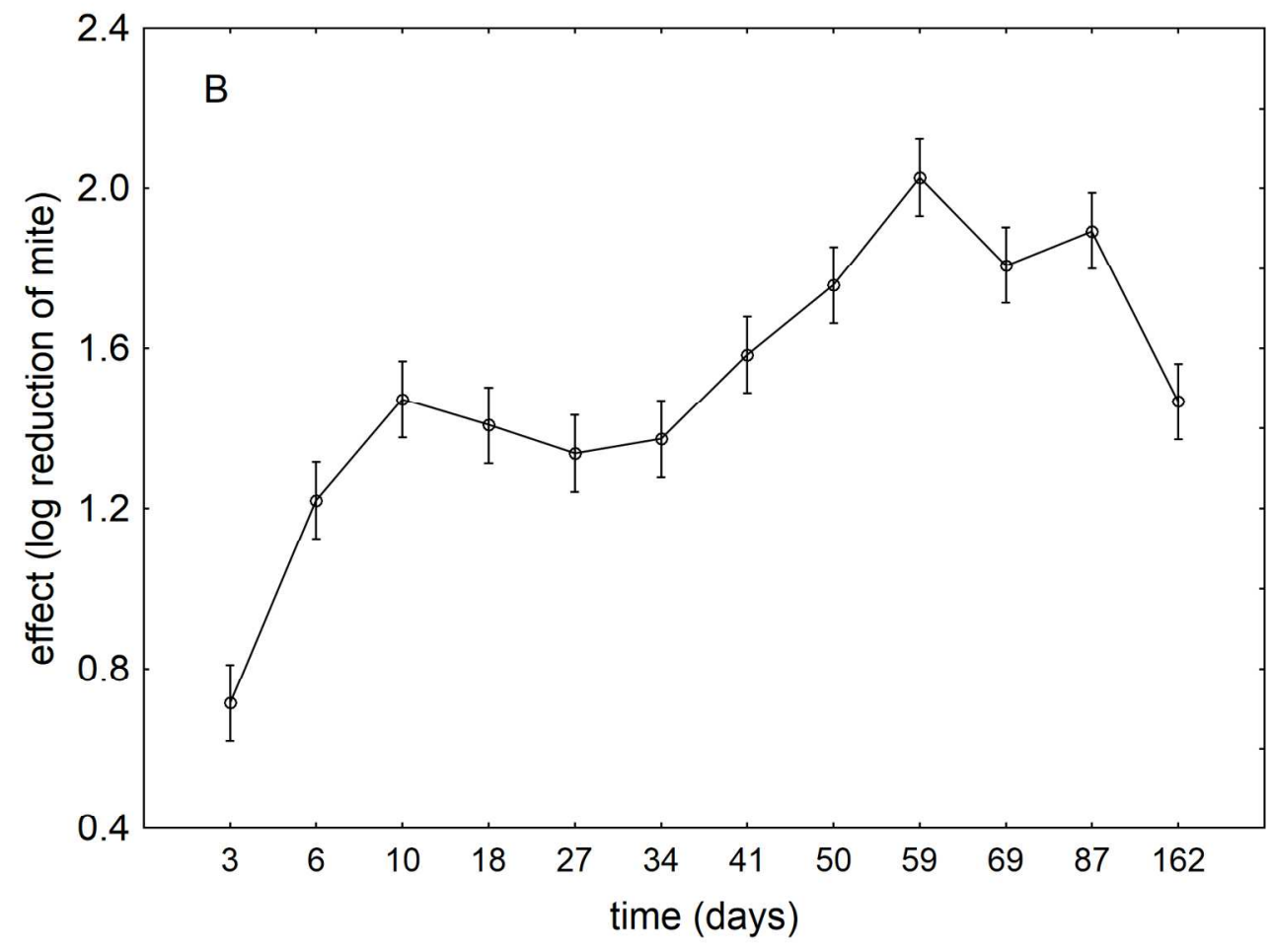

$515 \times 387 \mathrm{~mm}(96 \times 96 \mathrm{DPI})$ 


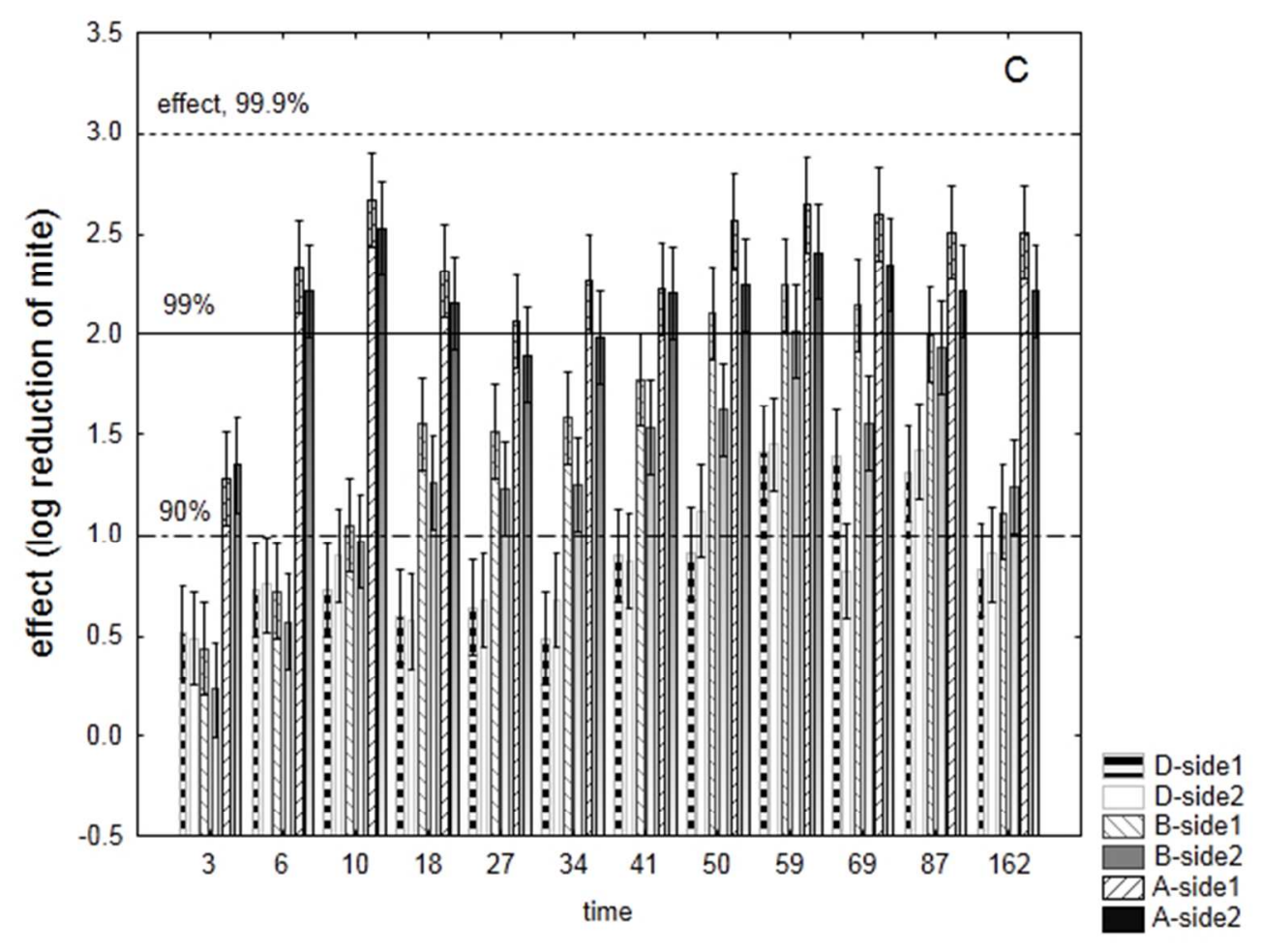

$165 \times 123 \mathrm{~mm}(96 \times 96$ DPI $)$ 


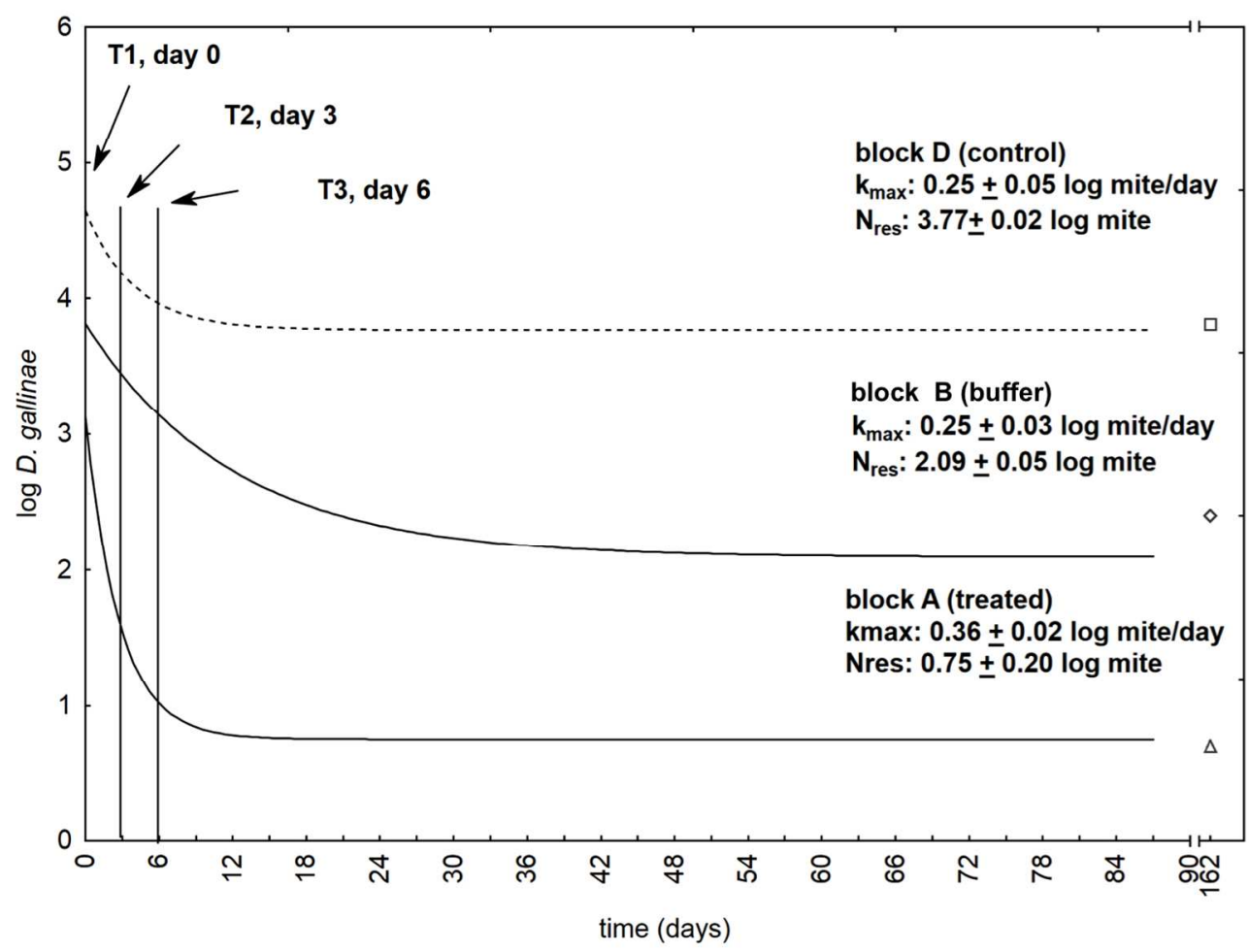

Fig. 4. Evolution of Dermanyssus gallinae. $\mathrm{kmax}=$ rate of population decrease; Nres, $/=$ survivors (mean values \pm standard error). T1 = 1st treatment; T2, 2nd treatment; T3, 3rd treatment.!! + The population evolution is fitted up to 87 days, though the last point shown indicates the mean values of the mite population after 162 days. !! +

$254 \times 190 \mathrm{~mm}(150 \times 150 \mathrm{DPI})$ 
1 Table S1. Scheme of the trial schedule

\begin{tabular}{|c|c|}
\hline Day & Events \\
\hline-3 & Placement of traps \\
\hline $0\left(\mathrm{~T}^{1}\right)$ & $\begin{array}{l}\text { Cardboard removal and count } \\
\text { First treatment with } \mathbf{R P 0 3}^{\mathrm{TM}} \\
\text { and Cardboard replacement }\end{array}$ \\
\hline $3\left(\mathrm{~T}^{2}\right)$ & $\begin{array}{l}\text { Cardboard removal and count, } \\
\text { Second treatment with RP03 } \\
\text { and Cardboard replacement }\end{array}$ \\
\hline $6\left(\mathrm{~T}^{3)}\right.$ & $\begin{array}{l}\text { Cardboard removal and count } \\
\text { Third treatment with } \mathbf{R P 0 3}{ }^{\mathrm{TM}}\end{array}$ \\
\hline 7 & Cardboard replacement \\
\hline 10 & Cardboard removal and count \\
\hline 15 & Cardboard replacement \\
\hline 18 & Cardboard removal and count \\
\hline 24 & Cardboard replacement \\
\hline 27 & Cardboard removal and count \\
\hline 31 & Cardboard replacement \\
\hline 34 & Cardboard removal and count \\
\hline 38 & Cardboard replacement \\
\hline 41 & Cardboard removal and count \\
\hline 47 & Cardboard replacement \\
\hline 50 & Cardboard removal and count \\
\hline 56 & Cardboard replacement \\
\hline 59 & Cardboard removal and count \\
\hline 66 & Cardboard replacement \\
\hline 69 & Cardboard removal and count \\
\hline 84 & Cardboard replacement \\
\hline 87 & Cardboard removal and count \\
\hline 159 & Cardboard replacement \\
\hline 162 & Cardboard removal and count \\
\hline
\end{tabular}

$\mathrm{T}^{1}: 1^{\text {st }}$ treatment; $\mathrm{T}^{2}: 2^{\text {nd }}$ treatment; $\mathrm{T}^{3:} 3^{\text {rd }}$ treatment 
1 Table S2. Number of Dermanyssus gallinae registered throughout the trial in Treated (A), Buffer (B) and

2 Control (D) blocks, on one side of the block line (1), on the other side of the block line (2) and average

3 on both lines (mean value of 1 and 2)

\begin{tabular}{|c|c|c|c|c|c|c|c|c|c|}
\hline \multirow[b]{2}{*}{ Days } & \multicolumn{9}{|c|}{ Mite mean count \pm SD } \\
\hline & $\begin{array}{l}\text { Block } \\
\text { D1 }\end{array}$ & $\begin{array}{l}\text { Block } \\
\text { D2 }\end{array}$ & $\begin{array}{l}\text { Block } \\
\text { D } \\
\text { (1and 2) }\end{array}$ & $\begin{array}{l}\text { Block } \\
\text { B1 }\end{array}$ & $\begin{array}{l}\text { Block } \\
\text { B2 }\end{array}$ & $\begin{array}{l}\text { Block } \\
\text { B } \\
\text { (1and 2) }\end{array}$ & $\begin{array}{l}\text { Block } \\
\text { A1 }\end{array}$ & $\begin{array}{l}\text { Block } \\
\text { A2 }\end{array}$ & $\begin{array}{l}\text { Block } \\
\text { A } \\
(\text { land } 2) \\
\end{array}$ \\
\hline $\begin{array}{l}-3 \\
\text { (Pre-treatment) }\end{array}$ & $\begin{array}{l}45,632 \pm \\
16,518\end{array}$ & $\begin{array}{l}50,935 \pm \\
15,131\end{array}$ & $\begin{array}{l}48,284 \pm \\
15.864\end{array}$ & $\begin{array}{l}11,275 \pm \\
6,998\end{array}$ & $\begin{array}{l}7,913 \pm \\
7,641\end{array}$ & $\begin{array}{l}9,594 \pm \\
7,430\end{array}$ & $\begin{array}{l}3,132 \pm \\
3,814\end{array}$ & $\begin{array}{l}2,965 \pm \\
5,528\end{array}$ & $\begin{array}{l}3,049 \pm \\
4,689\end{array}$ \\
\hline $\begin{array}{l}3 \\
\text { (After the first treatment) }\end{array}$ & $\begin{array}{l}15,688 \pm \\
10,121\end{array}$ & $\begin{array}{l}19,809 \pm \\
13,095\end{array}$ & $\begin{array}{l}17,640 \pm \\
11,651\end{array}$ & $\begin{array}{l}3,889 \pm \\
2,530\end{array}$ & $\begin{array}{l}3,798 \pm \\
2,469\end{array}$ & $\begin{array}{l}3,844 \pm \\
2,468\end{array}$ & $\begin{array}{l}152 \pm \\
237\end{array}$ & $\begin{array}{l}175 \pm \\
509\end{array}$ & $\begin{array}{l}163 \pm \\
392\end{array}$ \\
\hline $\begin{array}{l}6 \\
\text { (After the second treatment) }\end{array}$ & $\begin{array}{l}9,491 \pm \\
4,884\end{array}$ & $\begin{array}{l}9,802 \pm \\
5,076\end{array}$ & $\begin{array}{l}9,655 \pm \\
4,921\end{array}$ & $\begin{array}{l}2,701 \pm \\
2,441\end{array}$ & $\begin{array}{l}1,965 \pm \\
1,737\end{array}$ & $\begin{array}{l}2,333 \pm \\
2,124\end{array}$ & $\begin{array}{l}15 \pm \\
15\end{array}$ & $\begin{array}{l}8 \pm \\
6\end{array}$ & $\begin{array}{l}11 \pm \\
12\end{array}$ \\
\hline $\begin{array}{l}10 \\
\text { After the third treatment }\end{array}$ & $\begin{array}{l}10,062 \pm \\
6,823\end{array}$ & $\begin{array}{l}7,064 \pm \\
3,190\end{array}$ & $\begin{array}{l}8,684 \pm \\
5,602\end{array}$ & $\begin{array}{l}2,143 \pm \\
3,187\end{array}$ & $\begin{array}{l}989 \pm \\
1,363\end{array}$ & $\begin{array}{l}1,566 \pm \\
2,489\end{array}$ & $\begin{array}{l}8 \pm \\
12\end{array}$ & $\begin{array}{l}4 \pm \\
5\end{array}$ & $\begin{array}{l}6 \pm \\
10\end{array}$ \\
\hline 18 & $\begin{array}{l}13,363 \pm \\
8,235\end{array}$ & $\begin{array}{l}15,412 \pm \\
8,315\end{array}$ & $\begin{array}{l}14,388 \pm \\
8,234\end{array}$ & $\begin{array}{l}572 \pm \\
831\end{array}$ & $\begin{array}{l}1,102 \pm \\
1,842\end{array}$ & $\begin{array}{l}837 \pm \\
1,436\end{array}$ & $\begin{array}{l}13 \pm \\
12\end{array}$ & $\begin{array}{l}12 \pm \\
18\end{array}$ & $\begin{array}{l}12 \pm \\
15\end{array}$ \\
\hline 27 & $\begin{array}{l}12,344 \pm \\
7,093\end{array}$ & $\begin{array}{l}12,992 \pm \\
8,470\end{array}$ & $\begin{array}{l}12,668 \pm \\
7,718\end{array}$ & $\begin{array}{l}384 \pm \\
360\end{array}$ & $\begin{array}{l}901 \pm \\
1,694\end{array}$ & $\begin{array}{l}642 \pm \\
1,237\end{array}$ & $\begin{array}{l}16 \pm \\
9\end{array}$ & $\begin{array}{l}16 \pm \\
12\end{array}$ & $\begin{array}{l}16 \pm \\
10\end{array}$ \\
\hline 34 & $\begin{array}{l}16,765 \pm \\
9,842\end{array}$ & $\begin{array}{l}12,400 \pm \\
6,464\end{array}$ & $\begin{array}{l}14,582 \pm \\
8,511\end{array}$ & $\begin{array}{l}513 \pm \\
799\end{array}$ & $\begin{array}{l}727 \pm \\
1,070\end{array}$ & $\begin{array}{l}618 \pm \\
935\end{array}$ & $\begin{array}{l}13 \pm \\
13\end{array}$ & $\begin{array}{l}14 \pm \\
11\end{array}$ & $\begin{array}{l}14 \pm \\
12\end{array}$ \\
\hline 41 & $\begin{array}{l}7,810 \pm \\
6,576\end{array}$ & $\begin{array}{l}10,311 \pm \\
9,640\end{array}$ & $\begin{array}{l}9,061 \pm \\
8,243\end{array}$ & $\begin{array}{l}232 \pm \\
305\end{array}$ & $\begin{array}{l}585 \pm \\
1,001\end{array}$ & $\begin{array}{l}409 \pm \\
752\end{array}$ & $\begin{array}{l}14 \pm \\
11\end{array}$ & $\begin{array}{l}9 \pm \\
8\end{array}$ & $\begin{array}{l}11 \pm \\
11\end{array}$ \\
\hline 50 & $\begin{array}{l}6,465 \pm \\
3,759\end{array}$ & $\begin{array}{l}4,817 \pm \\
3,646\end{array}$ & $\begin{array}{l}5,641 \pm \\
3,749\end{array}$ & $\begin{array}{l}113 \pm \\
139\end{array}$ & $\begin{array}{l}419 \pm \\
760\end{array}$ & $\begin{array}{l}266 \pm \\
561\end{array}$ & $\begin{array}{l}6 \pm \\
5\end{array}$ & $\begin{array}{c}8 \pm \\
7\end{array}$ & $\begin{array}{l}7 \pm \\
6\end{array}$ \\
\hline 59 & $\begin{array}{l}2,579 \pm \\
2,833\end{array}$ & $\begin{array}{l}2,707 \pm \\
2,256\end{array}$ & $\begin{array}{l}2,643 \pm \\
2,529\end{array}$ & $\begin{array}{l}75 \pm \\
88\end{array}$ & $\begin{array}{l}160 \pm \\
277\end{array}$ & $\begin{array}{l}118 \pm \\
207\end{array}$ & $\begin{array}{l}5 \pm \\
4\end{array}$ & $\begin{array}{l}5 \pm \\
4\end{array}$ & $\begin{array}{l}5 \pm \\
4\end{array}$ \\
\hline 69 & $\begin{array}{l}2,752 \pm \\
2,596\end{array}$ & $\begin{array}{l}8,354 \pm \\
4,229\end{array}$ & $\begin{array}{l}5,553 \pm \\
4,477\end{array}$ & $\begin{array}{l}163 \pm \\
353\end{array}$ & $\begin{array}{l}580 \pm \\
990\end{array}$ & $\begin{array}{l}372 \pm \\
763\end{array}$ & $\begin{array}{l}6 \pm \\
7\end{array}$ & $\begin{array}{l}7 \pm \\
6\end{array}$ & $\begin{array}{l}6 \pm \\
7\end{array}$ \\
\hline 87 & $\begin{array}{l}3,189 \pm \\
2,720\end{array}$ & $\begin{array}{l}2,586 \pm \\
2,047\end{array}$ & $\begin{array}{l}2,888 \pm \\
2,395\end{array}$ & $\begin{array}{l}281 \pm \\
496\end{array}$ & $\begin{array}{l}261 \pm \\
601\end{array}$ & $\begin{array}{l}271 \pm \\
544\end{array}$ & $\begin{array}{l}17 \pm \\
53\end{array}$ & $\begin{array}{l}6 \pm \\
9\end{array}$ & $\begin{array}{l}11 \pm \\
38\end{array}$ \\
\hline 162 & $\begin{array}{l}9,913 \pm \\
8,020\end{array}$ & $\begin{array}{l}7,410 \pm \\
3,837\end{array}$ & $\begin{array}{l}8,662 \pm \\
6,334\end{array}$ & $\begin{array}{l}2,158 \pm \\
3,167\end{array}$ & $\begin{array}{l}1,738 \pm \\
3,322\end{array}$ & $\begin{array}{l}1,948 \pm \\
3,209\end{array}$ & $\begin{array}{l}9 \pm \\
14\end{array}$ & $\begin{array}{l}10 \pm \\
10\end{array}$ & $\begin{array}{l}9 \pm \\
12\end{array}$ \\
\hline
\end{tabular}




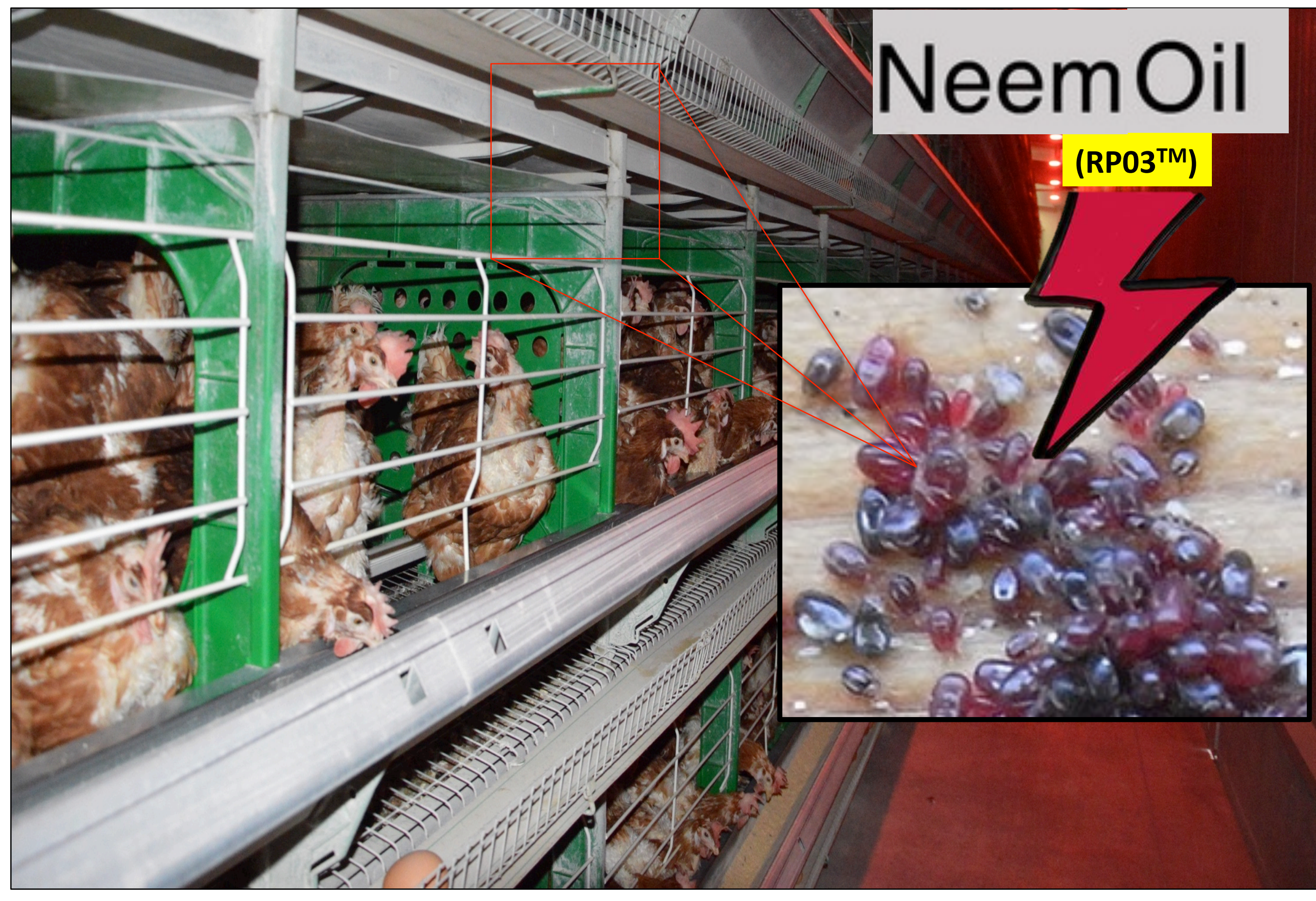




\section{HIGHLIGHTS}

$>$ Control of Dermanyssus gallinae, the poultry red mite, relies heavily on the use of chemicals

There is an urgent need to develop alternative products to avoid resistance and residues

$>$ A novel formulation of neem oil to treat laying hens against D. gallinae has been tested

$>$ The mite population was reduced by $99 \%$ after the second treatment, and effects persisted over 2 months

$>$ This is the first study on neem efficacy in laying hens housed within an enriched colony 

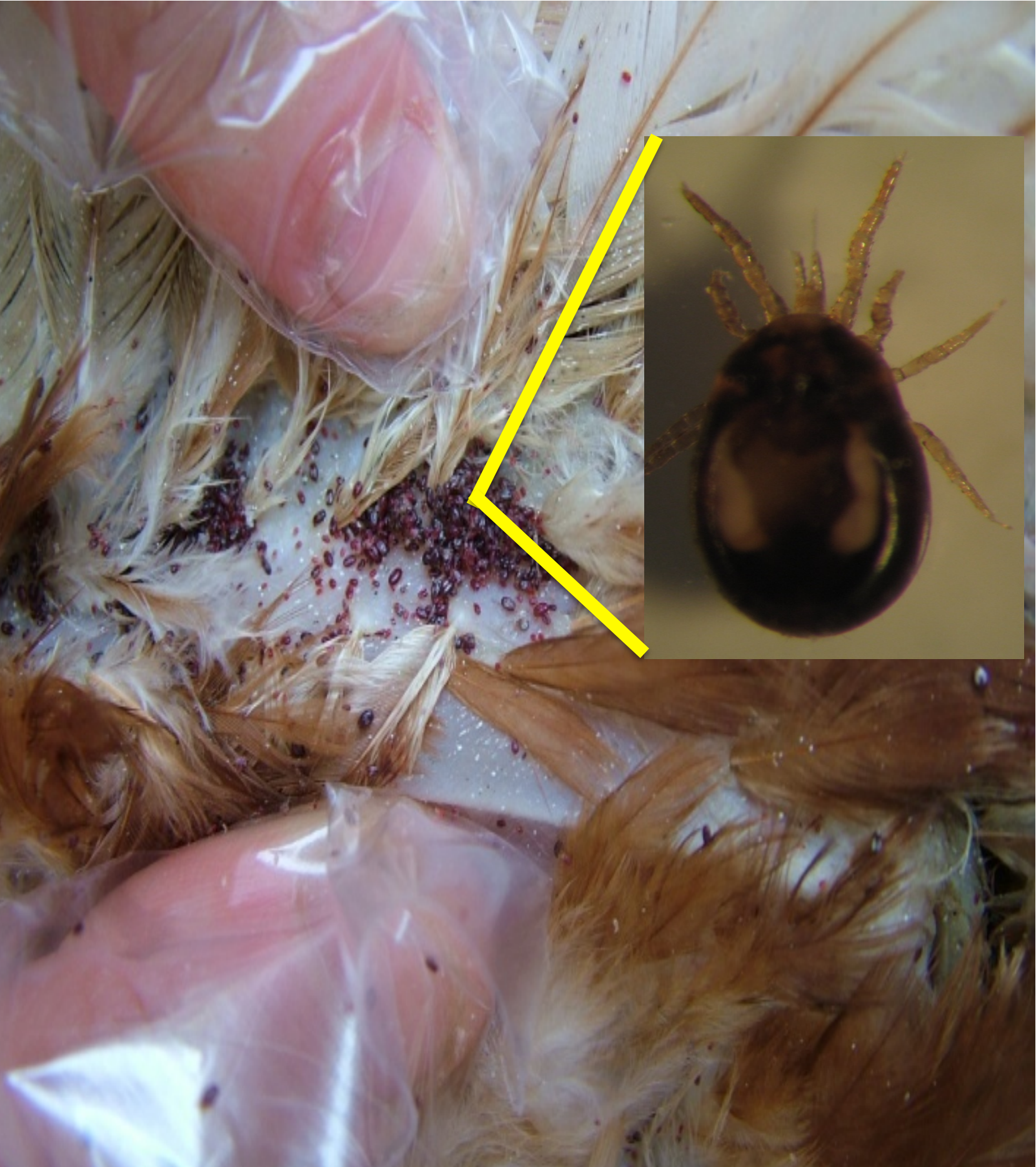


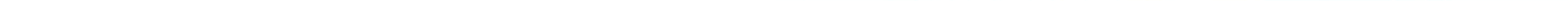




\section{Twitter}

No anymore chemicals! A novel formulation of neem oil reduce the mite poupulation by $99 \%$ after the second treatment. 